\title{
Site-Energies of Active and Inactive Pheophytins in the Reaction Center of Photosystem II from Chlamydomonas reinhardtii
}

\author{
K. Acharya ${ }^{1}$, B. Neupane ${ }^{1}$, V. Zazubovich ${ }^{3}$, R. T. Sayre ${ }^{4}$, R. Picorel ${ }^{5,6}$, M. Seibert ${ }^{5}$, \\ and R. Jankowiak ${ }^{1,2, *}$
}

${ }^{1}$ Department of Chemistry and ${ }^{2}$ Department of Physics, Kansas State University, Manhattan, KS 66506; ${ }^{3}$ Department of Physics, Concordia University, Montreal, Quebec, Canada; ${ }^{4} \mathrm{New}$ Mexico Consortium, Los Alamos, NM, 87544, and ${ }^{5}$ National Renewable Energy Laboratory, Golden, CO 80401

\begin{abstract}
It is widely accepted that the primary electron acceptor in various Photosystem II (PSII) reaction center $(\mathrm{RC})$ preparations is pheophytin $a(\mathrm{Pheo} a)$ within the D1 protein $\left(\mathrm{Pheo}_{\mathrm{D} 1}\right)$, while $\mathrm{Pheo}_{\mathrm{D} 2}$ (within the D2 protein) is photochemically inactive. The Pheo site energies, however, have remained elusive, due to inherent spectral congestion. While most researchers over the last two decades placed the $\mathrm{Q}_{\mathrm{y}}$-states of $\mathrm{Pheo}_{\mathrm{D} 1}$ and $\mathrm{Pheo}_{\mathrm{D} 2}$ bands near 678-684 $\mathrm{nm}$ and 668-672 nm, respectively, recent modeling [Raszewski et al. Biophys. J. 2005, 88, 986-998; Cox et al. J. Phys. Chem. B 2009, 113, 12364-12374] of the electronic structure of the PSII RC reversed the assignment of the active and inactive Pheos, suggesting that the mean site energy of $\mathrm{Pheo}_{\mathrm{D} 1}$ is near $672 \mathrm{~nm}$, whereas $\mathrm{Pheo}_{\mathrm{D} 2}(\sim 677.5 \mathrm{~nm})$ and $\mathrm{Chl}_{\mathrm{D} 1}(\sim 680 \mathrm{~nm})$ have the lowest energies (i.e., the $\mathrm{Pheo}_{\mathrm{D} 2}$-dominated exciton is the lowest excited state). In contrast, chemical pigment exchange experiments on isolated RCs suggested that both pheophytins have their $\mathrm{Q}_{\mathrm{y}}$ absorption maxima at 676-680 $\mathrm{nm}$ [Germano et al. Biochem. 2001, 40, 11472-11482; Germano et al. Biophys. J. 2004, 86, 1664-1672]. To provide more insight into the site energies of both Pheo and $\mathrm{PheO}_{\mathrm{D} 2}$ (including the corresponding $\mathrm{Q}_{\mathrm{x}}$ transitions, which are often claimed to be degenerate at $543 \mathrm{~nm}$ ) and to attest that the above two assignments are most likely incorrect, we studied a large number of isolated RC preparations from spinach and wild-type Chlamydomonas reinhardtii (at different levels of intactness) as well as the Chlamydomonas reinhardtii mutant (D2-L209H), in which the active branch Pheo ${ }_{\mathrm{D} 1}$ is genetically replaced with chlorophyll $a$ (Chl a). We show that the $\mathrm{Q}_{\mathrm{x}}-/ \mathrm{Q}_{\mathrm{y}}$-region site-energies of $\mathrm{Pheo}_{\mathrm{D} 1}$ and $\mathrm{Pheo}_{\mathrm{D} 2}$ are $\sim 545 / 680 \mathrm{~nm}$ and $\sim 541.5 / 670 \mathrm{~nm}$, respectively, in good agreement with our previous assignment [Jankowiak et al. J. Phys. Chem. B 2002, 106, 8803-8814]. The latter values should be used to model excitonic structure and excitation energy transfer dynamics of the PSII RCs.
\end{abstract}

${ }^{6}$ Permanent address: E. E. Aula Dei, CSIC, Zaragoza, Spain.

*Corresponding author; email: ryszard@ksu.edu 
Keywords: D2 mutant, electron acceptor, hole-burning, Photosystem II, reaction center

Abbreviations: Bacterial reaction center (BRC); charge separation (CS); charge separation time $\left(\tau_{c s}\right)$; chlorophyll $(\mathrm{Chl})$; continuous wave $(\mathrm{CW})$; Cytochrome $b_{559}$ (Cytb $\left.{ }_{559}\right)$; D1/D2-side pheophytins (Pheo $\left.\mathrm{D}_{1} / \mathrm{Pheo}_{\mathrm{D} 2}\right) ; \mathrm{D} 1 / \mathrm{D} 2$-side special pair chlorophylls $\left(\mathrm{P}_{\mathrm{D} 1} / \mathrm{P}_{\mathrm{D} 2}\right) ;$ D1-side accessory chlorophyll $\left(\mathrm{Chl}_{\mathrm{D} 1}\right)$; excitation energy transfer $(\mathrm{EET})$; fluorescence lifetime $\left(\tau_{f}\right)$; Glutamine (Gln); Huang-Rhys factor $(S)$; inhomogeneous broadening $\left(\Gamma_{\text {inh }}\right) ; \mathrm{L} / \mathrm{M}$-side bacteriochlorophylls $\left(\mathrm{BCh}_{\mathrm{L}, \mathrm{M}}\right) ; \mathrm{L} / \mathrm{M}$-side bacteriopheophytins $\left(\mathrm{BPheo}_{\mathrm{L}, \mathrm{M}}\right)$; laser intensity (I); non-photochemical hole burning (NPHB); photochemically active/inactive polypeptide chains in PSII RC (D1/D2) and in BRC (L/M); Photosystem II (PSII); reaction center (RC); single site absorption (SSA); site distribution function (SDF); triplet-bottleneck hole burning (TBHB); wild-type (WT); zero-phonon action (ZPA); zero-phonon hole (ZPH).

\section{Introduction}

The recent X-ray structure of the Photosystem II (PSII) reaction center (RC) at $1.9 \AA$ resolution $^{1}$ has confirmed that some of the general features of the PSII RC are homologous to those of the bacterial RC (BRC). ${ }^{2}$ The $\mathrm{S}_{1}\left(\mathrm{Q}_{\mathrm{y}}\right)$-electronic structure, excitation energy transfer (EET), and primary charge separation (CS) processes in the $\mathrm{D}_{1}-\mathrm{D}_{2}-\mathrm{Cytb}_{559} \mathrm{RC}$ complex of PSII (PSII RC) of plants, ${ }^{3-9}$ cyanobacteria, ${ }^{10-14}$ and algae ${ }^{15-18}$ have been the subjects of many timedomain $^{18-22}$ and frequency-domain studies ${ }^{23-28}$. Although in recent years consistent progress has been made in our understanding of the electronic structure and CS dynamics of the isolated PSII $\mathrm{RC},{ }^{10,29-31}$ an adequate global understanding has yet to be achieved. The key uncertainty in modeling of its optical spectra (independent of the level of the excitonic theory involved) is that different sets of data are interpreted in the context of different pigment site-energies ${ }^{10,22,29,31-33}$ that cannot be reliably calculated due to the complex protein environment. Instead, the search for realistic site energies is always guided by experimental constraints and aided by fitting algorithms. ${ }^{31,32,34-37}$ In particular, the focus of the current study is on the site energies of the active and inactive pheophytins $\left(\mathrm{Pheo}_{\mathrm{D} 1}\right.$ and $\mathrm{Pheo}_{\mathrm{D} 2}$, respectively) in the isolated PSII RC from wild-type (WT) Chlamydomonas (C.) reinhardtii and its D2-L209H mutant. While most researchers over the last two decades surmised that the $\mathrm{Q}_{\mathrm{y}}$-states of $\mathrm{Pheo}_{\mathrm{D} 1}$ and $\mathrm{Pheo}_{\mathrm{D} 2}$ bands 
were at $\sim 678-684 \mathrm{~nm}$ and $\sim 668-672 \mathrm{~nm}$, respectively, recent modeling ${ }^{11,14,38}$ of the electronic structure of the PSII RC reversed the location of the active and inactive Pheos, suggesting that the mean site energy of Pheo $\mathrm{D}_{1}$ is near $672 \mathrm{~nm}$, whereas $\mathrm{Pheo}_{\mathrm{D} 2}(\sim 677.5 \mathrm{~nm})$ and $\mathrm{Ch}_{\mathrm{D} 1}(\sim 680$ $\mathrm{nm})^{11,14,38}$ have the lowest energies (i.e., the Pheo $\mathrm{D}_{2}$-dominated exciton is the lowest excited state of the RC). The latter would allow one to explain the presence of narrow (persistent) holes burned into the lowest energy state spectrum, as excitation of $\mathrm{Pheo}_{\mathrm{D} 2}$ would not lead to charge separation. ${ }^{38}$ This assumption, however, is not necessary, as a broad distribution of charge separation rates ${ }^{4,6,21}$ can explain the possibility of burning very narrow holes. For example, it has been shown that there are fractions of both P680- and P684-type RCs, where charge separation is too slow to compete with fluorescence at $5 \mathrm{~K} .{ }^{4,39,40}$ Besides, a typical fractional depth of saturated ZPHs at $680 \mathrm{~nm}$ are $25 \%{ }^{4}$ and not $15 \%$, as reported $\mathrm{in}^{38}$. Such holes are not achievable within the Cox et al. model $^{38}$, as Pheo $\mathrm{D}_{\mathrm{D} 2}$ contributes only $17 \%$ to the lowest state in their model. Thus we favor an interpretation that is also consistent with recent transient absorption experiments at $77 \mathrm{~K}$ on the isolated PSII RCs from spinach, where the existence of a very slow channel for charge separation was observed. ${ }^{5}$ The combination of femtosecond pumpprobe transient absorption experiments with exchange of selected Pheos (i.e., chemical exchange of Pheo ${ }_{D 1}$ and $\mathrm{Pheo}_{\mathrm{D} 2}$ with 13'-deoxy-13'-hydroxy-pheophytin a) suggested that both pheophytins in the PSII RC have their $\mathrm{Q}_{\mathrm{y}}$-transitions at $676-681 \mathrm{~nm} .^{7,41,42}$ To provide more insight into the site energies of both $\mathrm{Pheo}_{\mathrm{D} 1}$ and $\mathrm{Pheo}_{\mathrm{D} 2}$, and to prove that the above assignment is unlikely correct, we compare data obtained for the RC from spinach with those generated for WT C. reinhardtii and its D2-L209H mutant. In this mutant the active branch Pheo $_{\mathrm{D} 1}$ is replaced with chlorophyll $a(\mathrm{Chl} a)$ by site-directed mutagenesis ${ }^{43}$ on the $p s b D$ gene.

Figure 1 (left frame) shows a schematic arrangement of the six Chl and two Pheo molecules for the PSII RC from Thermosynechococcus (T.) vulcanus based on Ref. ${ }^{1}$; the $\mathrm{P}_{\mathrm{D} 1}$ and 
$\mathrm{P}_{\mathrm{D} 2}$ Chls are analogous to the $\mathrm{P}_{\mathrm{L}}$ and $\mathrm{P}_{\mathrm{M}} \mathrm{BChls}$ of the bacterial special pair, respectively, while the $\mathrm{Ch}_{\mathrm{D} 1, \mathrm{D} 2}$ an Pheo ${ }_{\mathrm{D} 1, \mathrm{D} 2}$ molecules correspond to the monomeric $\mathrm{BCh}_{\mathrm{L}, \mathrm{M}}$ and the $\mathrm{BPheo}_{\mathrm{L}, \mathrm{M}}$ molecules of the BRC. ${ }^{2}$ The D1 and D2 polypeptides are homologous with the L and M polypeptides of the BRC, respectively. ${ }^{17,44}$ By analogy with the BRC, it is also believed that the $\mathrm{P}_{\mathrm{D} 1} / \mathrm{P}_{\mathrm{D} 2}, \mathrm{Chl}_{\mathrm{D} 1}$, and $\mathrm{Pheo}_{\mathrm{D} 1}$ molecules participate in primary charge separation in the PSII RC. ${ }^{29-}$ ${ }^{32}$ An obvious difference between the PSII RCs and BRCs is that the former contains two additional (peripheral) Chls, which are also shown in the left frame of Figure 1. In addition, a sample heterogeneity and spectral congestion of pigments (with comparable couplings) in the PSII RC and the lack of crystals of isolated D1-D2-Cyt $b_{559}$ complexes, make it difficult to describe the excitonic structure of the isolated PSII RC. The right frame of Figure 1 shows the pigments along with their ligands of the D2-L209H mutant mentioned above, in which the active $\mathrm{PheO}_{\mathrm{D} 1}$ has been replaced with chlorophyll a $(\mathrm{Chl} a)$. The cofactor arrangement in the active (D1) and inactive (D2) branches of the PSII RC was taken from the very recent crystal structure of T. vulcanus at $1.9 \AA$ resolution, PDB ID 3ARC. ${ }^{1}$

To our knowledge, there are only a few studies of the isolated algal PSII RC from C. reinhardtii because such complexes are difficult to prepare. ${ }^{10,15-18}$ We anticipate that the structural asymmetry introduced into the RC complex in the case of the C. reinhardtii D2-L209H mutant will shed more light on the site-energy of the active pheophytin. This strategy of replacing selected bacteriopheophytins (BPheos) with bacteriochlorophylls (BChls) was originally developed in BRCs. ${ }^{45-47}$ Similar pigment replacements have been accomplished in PSII RCs using chemically modified Pheos along with detergent extraction and pigment reconstitution approaches. ${ }^{7,41,48}$ However, it is not clear to what extent the latter approach modifies and/or destabilizes the excitonic structure of the RCs. Site-directed mutagenesis approaches should, in principle, give more precise replacement and a less distorted system than chemical modification, 
and have the additional advantage that intact PSII complexes (thylakoids) as well as smaller PSII sub-fractions (including RCs) can be characterized biophysically. It has recently been demonstrated that the introduction of a potential Mg ligand (D1-L210H) over the center of the $\mathrm{Pheo}_{\mathrm{D} 2}$ macrocycle ring resulted in the replacement of Pheo 2 with a Chl $a \cdot{ }^{10}$ In this case, the kinetics of primary charge separation were not substantially altered in the D1-L210H mutant, indicating that the Chl substitution for the $\mathrm{Pheo}_{\mathrm{D} 2}$ in the inactive branch did not significantly perturb the energetics of the primary electron donor/acceptor pair. ${ }^{10}$ It was also shown that Pheo $_{D 2} Q_{x}$ band is blue shifted in comparison with the $\mathrm{Q}_{\mathrm{x}}$ band of Pheo $\mathrm{O}_{\mathrm{D} 1}$ (active). ${ }^{10}$

We present below absorption and hole burned (HB) spectra of WT C. reinhardtii and its D2- mutant (D2-L209H), obtained under various conditions as well as some new results from our modeling studies. A discussion of the primary electron donor(s) and the possibility of $\mathrm{P}_{\mathrm{D} 1}$ and $\mathrm{Chl}_{\mathrm{D} 1}$ electron transfer pathways being present in isolated PSII RC is reported in ${ }^{49}$. In the current study we focus on the assignment of the $\mathrm{Q}_{\mathrm{y}^{-}}$and $\mathrm{Q}_{\mathrm{x}}$-states of Pheo $\mathrm{D}_{\mathrm{D} 1}$ and $\mathrm{Pheo}_{\mathrm{D} 2}$. The results reported below indicate that the $\mathrm{Pheo}_{\mathrm{D} 1}-\mathrm{Q}_{\mathrm{x}}$ and $\mathrm{Pheo}_{\mathrm{D} 2}-\mathrm{Q}_{\mathrm{x}}$ transitions lie on the low and high energy sides, respectively, of the single Pheo- $\mathrm{Q}_{\mathrm{x}}$ absorption band, in perfect agreement with data obtained previously with the PSII RCs from spinach. ${ }^{10,26,34,50}$ We also demonstrate that the replacement of the $\mathrm{Pheo}_{\mathrm{D} 1}$ with a $\mathrm{Chl} a$ leads to results which are in agreement with simple modeling studies of the absorption difference spectrum. We show that in contrast to the D1L210H mutant (with Pheo 2 replaced by $\mathrm{Chl} a^{10}$ ), where the kinetics of primary charge separation were not substantially altered, ${ }^{10}$ the D2-L209H mutant exhibits significant changes in the energetics of the primary electron donor/acceptor pair. Finally, we argue that it is unlikely that $\mathrm{Pheo}_{\mathrm{D} 2}$ dominates the lowest-energy excited state (and contributes to the zero-phonon action (ZPA) spectra) as suggested recently. ${ }^{38} \mathrm{~A}$ new interpretation of the origin of the nonresonant (persistent) hole bleached in the isolated PSII RC is also provided. We anticipate that the data 
presented in this paper will allow us to refine the models of the electronic structure of the PSII $\mathrm{RC}$ by providing additional constraints (i.e., proper site energies of both the active and inactive pheophytins) for future excitonic calculations of optical spectra (research in progress).

\section{Materials and Methods}

\subsection{Preparation of PSII RC from WT C. reinhardtii and its D2-L209H mutant.} Photosystem II RC preparations from C. reinhardtii containing $\sim 6$ Chls per 2 Pheos in the WT, and $\sim 7$ Chls and 1 Pheo in the D2-L209H mutant (note this mutant is incapable of photosynthetic growth because of the absence of an active-Pheo and thus was grown in the dark in TAP medium) were prepared from both thylakoids and PSII-enriched membranes following the method of Nanba and Satoh ${ }^{3}$ with important modifications. ${ }^{18}$ To obtain the D2-L209H mutant studied in the present work, we used a transgenic (site-directed mutagenesis) approach to modify the pigment composition of the C. reinhardtii PSII RC. A histidine, a common Chl ligand, was introduced to the $\mathrm{D} 2$ protein over the macrocycle ring of the active branch Pheo $\mathrm{D}_{\mathrm{D}}$. Thylakoids or PSII-enriched membranes (around $100 \mathrm{mg} \mathrm{Chl}$ ) were resuspended in buffer A (20 mM Bis-Tris, $\mathrm{pH}=6.5,1.5 \mathrm{mM}(\mathrm{w} / \mathrm{v})$ taurine, and $35 \mathrm{mM} \mathrm{NaCl})$, and treated with $6 \%(\mathrm{w} / \mathrm{v})$ Triton $\mathrm{X}-100$ (final concentration) at a final chlorophyll (Chl) concentration of $0.5 \mathrm{mg} \mathrm{Chl} / \mathrm{mL}$. The detergent was added drop-wise from a $30 \%(\mathrm{w} / \mathrm{v})$ solution, and the suspension was incubated for $2 \mathrm{~h}$ at $4^{\circ} \mathrm{C}$ with gentle stirring in the dark. The solution was centrifuged at 40,000 $\mathrm{xg}$ for $30 \mathrm{~min}$, and the resultant supernatant was loaded onto a Toyopearl TSK DEAE 650s column $(30 \times 1 \mathrm{~cm})$, preequilibrated with buffer B (20 mM Bis-Tris, $\mathrm{pH}=6.5,1.5 \mathrm{mM}$ taurine, $35 \mathrm{mM} \mathrm{NaCl}$, and $0.35 \%$ $[\mathrm{w} / \mathrm{v}]$ Triton $\mathrm{X}-100)$ at a flow rate of $3-4 \mathrm{~mL} / \mathrm{min}$. The large pellet from the centrifugation was still quite green, and it was re-suspended in the same buffer without Triton, incubated for 10 min, and centrifuged again under the same conditions. The new green supernatant was added to 
the previous one on the column. Note that the final bound green material remained at about the middle of the column in contrast to the observation with similar material isolated from spinach, which remained at the very top of the column. Spinach material seems to bind more strongly to this column than that from Chlamydomonas. A similar observation was reported by Alizadeh et al. ${ }^{16}$ using the Chlamydomonas F54-14 mutant (a PSI- and chloroplastic ATPase-defective double mutant). The column was then washed overnight with the same buffer B at a flow-rate of $3 \mathrm{~mL} / \mathrm{min}$ until the peak at $435 \mathrm{~nm}$ was a little lower that that at $417 \mathrm{~nm}$. At this point, the remaining green material was eluted with a $35-300 \mathrm{mM} \mathrm{NaCl}$ linear gradient in the same buffer, 3-mL fractions were collected, and the RCs eluted at around $90 \mathrm{mM} \mathrm{NaCl}$. In the case of the D2L209H mutant, most of the recovered material showed a room temperature absorption peak at around $675 \mathrm{~nm}$, and the material was stored without further treatment under liquid $\mathrm{N}_{2}$ until use. WT RCs exhibited an absorption peak at around $675.5 \mathrm{~nm}$ (the first 3-4 colored fractions that eluted at around $90 \mathrm{mM} \mathrm{NaCl}$ ), but the other fractions showed maxima at $\geq 676 \mathrm{~nm}$, probably due to some contamination with LHCII or PSI components. The fractions with maxima at around $675.5 \mathrm{~nm}$ were pooled for $\mathrm{Cu}^{2+}$-IMAC chromatography as in Ref. ${ }^{51}$, using a Chelating Sepharose Fast-Flow (GE Healthcare) column to eliminate some minor Chl $b$-containing pigment-protein complex contaminant. The green material was eluted with a 0-50 mM Imidazol gradient. Pigment quantification of the preparations was done after extraction with $80 \%(\mathrm{v} / \mathrm{v})$ acetone using the method in Ref. ${ }^{52}$ Our typical RC preparation from spinach contained 5.85 Chl/2 Pheo and that from WT Chlamydomonas contained 5.55 Chl/2 Pheo. If we assume 6.0 Chl/2Pheo in spinach we obtained about 5.7 Chl/2 Pheo in our WT Chlamydomonas PSII RC preparation. This somewhat lower Chl content of our preparations compared with other PSII RC material is most probably due to a reproducibly lower carotenoid content in our preparations as compared to those from other laboratories; carotenoid bands were taken into account in our pigment 
calculations). Using the same quantification methodology, our non-active D2-L209H mutant RCs contained about seven Chl per one Pheo, demonstrating that in this mutant one Pheo is been replaced for one Chl.

2.2. Spectroscopic measurements. The hole burning apparatus used for this study was described in detail elsewhere. ${ }^{53,54}$ Briefly, absorption and hole spectra were recorded with a Bruker HR120 Fourier transform spectrometer. Absorption and hole-burned spectra were obtained at a resolution of $4 \mathrm{~cm}^{-1}$ and $0.5 \mathrm{~cm}^{-1}$, respectively. A Coherent CR699-21 ring dye laser (linewidth of $0.07 \mathrm{~cm}^{-1}$ ), pumped with a $6 \mathrm{~W}$ Coherent Innova argon-ion laser, was used to burn the holes. The persistent NPHB spectra reported in the figures correspond to the post-burn absorption spectrum minus the pre-burn absorption spectrum. The triplet bottleneck hole spectra correspond to absorption spectrum with laser on minus the spectrum with laser off. Burn intensities and times are given in the figure captions. The sample temperature was maintained at $5 \mathrm{~K}$ using a Janis 8-DT Super Vari-Temp liquid helium cryostat. The excitation source for the fluorescence experiments was a Coherent UV argon-ion laser operating at $496.5 \mathrm{~nm}$. Fluorescence was dispersed at a resolution of $0.1 \mathrm{~nm}$ by a Princeton Instrument Acton SP-2300 monochromator, equipped with a back-illuminated, $\mathrm{N}_{2}$-cooled CCD camera. Care was taken to ensure that reabsorption effects were negligible.

\subsection{Monte Carlo simulations of the WT minus the mutant RC absorption difference}

spectrum. To model absorption changes introduced by the mutation, we carried out simple excitonic calculations using MathCad 12.0. Transition dipole moments and coupling between chromophores were calculated as in Ref. ${ }^{11}$ However, due to the significant shift in the position of the central magnesium out of the chlorin plane, which was revealed in the recent crystal structure, the transition dipole moments were taken to extend from the ring I nitrogen (N-B) to 
the ring III nitrogen (N-D) rather than from the central $\mathrm{Mg}$ to $\mathrm{N}-\mathrm{D}$, and the center of the Chl molecule was taken to be at the averaged position of the four ring nitrogen atoms, rather than at the central magnesium. A Frenkel Hamiltonian matrix (static lattice approximation) for the PSII RC chromophores was constructed (see section 3.5); for each iteration of the Monte Carlo simulations, site energies were added randomly according to a Gaussian distribution, mimicking the site distribution function (SDF) of the chromophore. A simple fitting algorithm was used to find optimized parameters (i.e., site energies and the width of the SDF) to achieve simultaneously good fits to the absorption for the RCs from WT C. reinhardtii and the D2L209H mutant, as well as the difference between the latter two spectra.

\section{Results}

\subsection{Low temperature absorption spectra of the RC from WT C. reinhardtii and its D2-}

L209H mutant-site energies of Pheo ${ }_{D 1}$ and Pheo $_{D 2}$. Absorption spectra of the WT RC from C. reinhardtii and its D2-mutant are shown in Figure 2, as blue (a) and black (b) curves, respectively. According to pigment extraction with $80 \%(\mathrm{v} / \mathrm{v})$ acetone and comparison with spinach RC data obtained as in Ref., ${ }^{52}$ we established that our WT RC and D2 mutant contained about $6 \mathrm{Chl} a / 2$ Pheo $a$ and $7 \mathrm{Chl} a / 1$ Pheo $a$, respectively (the measured values were 5.7 and 6.5-7, respectively; however, see the comments in Material and Methods, Section 2.1). Note that our WT RC preparation (see curve a in Figure 2) has a 5K absorption maximum near $679.5 \mathrm{~nm}$ with a noticeable shoulder near $685 \mathrm{~nm}$. Spectra a and b were normalized over a broad spectral range of 500-700 nm, assuming that the integrated absorbance of the WT PSII and D2-L209H mutant RCs should be about 7.0 (in Chl $a$ units) and 7.5, respectively. The difference originates from the fact that the mutant has Chl $a$ (instead of Pheo $\left._{\mathrm{D} 1}\right)$ in the active D1-protein branch and the Pheo oscillator strength in the protein environment is $50 \%$ that of $\mathrm{Chl} a^{7,55}$, for convenience 
normalized to unity. The difference spectrum between mutant and WT RC is given by the red curve (c) in Figure 2. The overall absorption decrease near $684 \mathrm{~nm}$ in curve (c) corresponds to about 0.3 in Chl $a$ units. The intensity gain at $\sim 679 \mathrm{~nm}$ is bigger than the loss at $\sim 684 \mathrm{~nm}$ because the oscillator strength of the $\mathrm{Chl} a$ is higher than that of Pheo $a$. A theoretical description of this spectrum is shown in Figure 2. Here we note only that the shape of curve (c) suggests that the site energy of $\mathrm{Chl} a$ in the Pheo $\mathrm{D}_{1}$ binding pocket shifts to the blue. The fluorescence from WT C. reinhardtii RCs peaks near $685 \mathrm{~nm}$ (data not shown).

Curves $\mathrm{a}^{\prime}$ and $\mathrm{b}^{\prime}$ in the inset of Figure 2 correspond to the normalized $\mathrm{Q}_{\mathrm{x}}$ band of the WT C. reinhardtii RC and its D2-L209H mutant. The difference between curves $\mathrm{a}^{\prime}$ and $\mathrm{b}^{\prime}$ (curve $\mathrm{c}^{\prime}$ ) corresponds to the removal of $\mathrm{Pheo}_{\mathrm{D} 1}$ (red curve in the inset), proving that the absorbance difference in $\mathrm{Q}_{\mathrm{y}}$ near $684 \mathrm{~nm}$ (see curve c) indeed originates from the genetically replaced mutation of Pheo $a\left(\mathrm{Pheo}_{\mathrm{D} 1}\right)$ to $\mathrm{Chl} a$. We would like to make it clear that the $684 \mathrm{~nm}$ bleach does not reflect the site energy of Pheo ${ }_{\mathrm{D} 1}$; rather, it reflects changes to the lowest exciton band in the $\mathrm{RC}$ mutant (vide infra). We hasten to add that the coupling constants between chlorins in the $\mathrm{Q}_{\mathrm{x}}$ region are about one order of magnitude weaker than those in the $\mathrm{Q}_{\mathrm{y}}$-region. ${ }^{56}$ This is why the entire $\mathrm{Q}_{\mathrm{x}}$ absorption band near $544 \mathrm{~nm}$ in WT RC corresponds both to the active and inactive pheophytins, since the $\mathrm{Q}_{\mathrm{x}}$ band of Chl $a$ lies near $580 \mathrm{~nm}$. Thus the bleach at $\sim 545$ and $\sim 684 \mathrm{~nm}$ corresponds definitively to the replacement of active Pheo ${ }_{\mathrm{D} 1}$ with $\mathrm{Chl} a$. This in turn indicates that the $\mathrm{Q}_{\mathrm{x}}$-transition of $\mathrm{Pheo}_{\mathrm{D} 2}$ must be near $541.5 \mathrm{~nm}$; the site energy of $\mathrm{Q}_{\mathrm{y}}$ Pheo $_{\mathrm{D} 2}$ will be discussed below. Here, it suffice to say that the relative positions of the $\mathrm{Q}_{\mathrm{x}}$-transitions of active and inactive Pheos in C. reinhardtii are in good agreement with the same $\mathrm{Q}_{\mathrm{x}}$-transitions observed in isolated $\mathrm{RC}$ from spinach, where the localized $\mathrm{Q}_{\mathrm{x}}$-transitions of Pheo $\mathrm{D}_{\mathrm{D} 1}$ and Pheo $\mathrm{D} 2$ were demonstrated to lie at 544.4 and 541.2, respectively. ${ }^{26,34}$ In addition, we found that in our most 
intact WT RC from C. reinhardtii the entire $\mathrm{Q}_{\mathrm{x}}$-band lies near $544 \mathrm{~nm}$ (not at $543 \mathrm{~nm}$, as typically observed in isolated spinach $\left.\mathrm{RCs}^{7,24,41}\right)$. The red-shifted $\mathrm{Q}_{\mathrm{x}}$ bleach of active Pheo ${ }_{\mathrm{D} 1}$ near $545 \mathrm{~nm}$ is in perfect agreement with data obtained for intact spinach PSII core, ${ }^{58,59}$ suggesting that our isolated RCs are intact. The green curve $d$ is the theoretical fit of curve $c$ that was obtained using Pheo ${ }_{\mathrm{D} 1}$ site energy in WT RC at $679.8 \mathrm{~nm}$, which was blue-shifted by $125 \mathrm{~cm}^{-1}$ (due to $\mathrm{Pheo}_{\mathrm{D} 1}$ replacement with $\mathrm{Chl} a$ ) in the mutant (see section 3.5. for details). Here we just note that the Pheo ${ }_{\mathrm{D} 1}$ site energy used in this fit is $679.8 \mathrm{~nm}$. In view of the above data, we conclude that it is doubtful that the site energy of Pheo ${ }_{\mathrm{D} 1}$ lies near $672 \mathrm{~nm}$, as assumed recently in Refs. ${ }^{11,38}$ (vide infra). Thus, it is not likely that the exciton realizations may lead to a significant $\mathrm{PheO}_{\mathrm{D} 2}$ contribution to the lowest energy exciton, as suggested by Cox et al. ${ }^{38}$.

\subsection{Comparison of absorption, persistent, and transient hole spectra obtained for the}

RCs from C. reinhardtii and spinach. Frames A and B in Figure 3 show $\mathrm{Q}_{\mathrm{y}}$ absorption spectra obtained for RCs from C. reinhardtii and spinach, respectively. There is no indication that any of these two samples are contaminated with antenna complexes, i.e., both have $6 \mathrm{Chl} a / 2$ Pheo $a$, and exhibit no bleaching and/or emission bands typically observed in PSII antenna complexes. $^{40,60}$ The corresponding insets in frames $\mathrm{A}$ and $\mathrm{B}$ show $\mathrm{Q}_{\mathrm{x}}$ absorption band of pheophytins located near $544 \mathrm{~nm}$ (frame A) and $543 \mathrm{~nm}$ (frame B). As expected, the more intact sample (frames A, C, and E) has red-shifted peaks of $\mathrm{Q}_{\mathrm{y}^{-}}$and $\mathrm{Q}_{\mathrm{x}}$-absorption bands, as well as the position of the lowest-energy bands, in agreement with spectra obtained for RC from intact PSII core samples. ${ }^{14,58,59}$ Frames C and D show (nonresonant) persistent saturated holes obtained with $\lambda_{\mathrm{B}}$ of $665.0 \mathrm{~nm}$. Non-resonant holes appear as a result of downhill energy transfer. The hole depths of the broad (saturated) holes, obtained under identical conditions and shown in frames $\mathrm{C}$ (C. reinhardtii) and D (spinach), are 4.6\% and 3.5\%, respectively. Although hole shapes are similar, the broad hole in C. reinhardtii, located at $683.8 \mathrm{~nm}$, is about $3.2 \mathrm{~nm}$ red-shifted in 
comparison with the hole typically obtained for RCs isolated from spinach. ${ }^{25,26,61}$ The origin of the broad 683.8 and $680.6 \mathrm{~nm}$ holes will be discussed in section 4.1 . Here we only note that both persistent holes shown in frames $\mathrm{C}$ and $\mathrm{D}$ have weak responses in the $\mathrm{Q}_{\mathrm{x}}$ region of $\mathrm{Pheo}_{\mathrm{D} 1}$ near $545 \pm 1$ and $544 \pm 1 \mathrm{~nm}$, respectively. An example of $\mathrm{Q}_{x}$ bleach in spinach $\mathrm{RC}$ is shown in the inset of frame D.

In contrast to persistent holes, the transient, non-line narrowed spectra shown in frames $\mathrm{E}$ and $\mathrm{F}\left(\lambda_{\mathrm{B}}=665.0 \mathrm{~nm}\right)$ are very different; the hole in C. reinhardtii (frame E) has two components at 672.7 and $683.3 \mathrm{~nm}$ with a positive feature near $679 \mathrm{~nm}$. The fractional hole depth at $683.3 \mathrm{~nm}$ (measured with a laser intensity (I) of $100 \mathrm{~mW}$ ) is $22.5 \%$. The large nonresonant transient hole, obtained under identical conditions for spinach RCs, is blue shifted to $680.0 \mathrm{~nm}$ (although slightly red-shifted holes near 681-682 nm have been previously observed in isolated RCs from spinach ${ }^{25,26,61}$ ) and has a smaller fractional depth of $9.8 \%$. Note the shape of this transient hole is exactly the same as previously observed in spinach PSII RCs ${ }^{25,26,61}$ with a bleach near $680 / 681 \mathrm{~nm}$ and a weak shoulder near $683 / 684 \mathrm{~nm}^{26}$, which we assigned previously to P680 and P684 RCs, respectively ${ }^{4}$. That is, we proposed that in isolated spinach RCs, transient holes at $\sim 680-681 \mathrm{~nm}$ and $\sim 684 \mathrm{~nm}$ correspond to the triplet bottleneck holes, originating from P680- and P684-type RCs and reflecting the gross heterogeneity of PSII RCs (the P684-band is a subset of RCs that are more intact than P680-type RCs). ${ }^{4}$ This suggestion is consistent with data presented in Figure 3. Another striking difference between the transient holes obtained for C. reinhardtii and spinach $\mathrm{RCs}$ is in the $\mathrm{Q}_{\mathrm{x}}$ region. As previously observed there is no bleaching in this region for transient spectra obtained for spinach RCs (see the inset in frame F), whereas the $\mathrm{Q}_{\mathrm{x}}$ Pheo band clearly shifts in C. reinhardtii RCs as shown in the inset of frame E. 
3.3. Optical spectra obtained for the C. reinhardtii D2-L209H mutant. Spectra a and a' in Figure 4 show absorption and emission (with a (0,0)-band maximum near $681 \mathrm{~nm}$ ) spectra of the D2-L209H mutant. The lowest-energy state (see curve b corresponding to a nonresonant persistent hole obtained with $665 \mathrm{~nm}$ excitation) is near $680 \mathrm{~nm}$, revealing a very small Stokes shift of $\sim 20 \mathrm{~cm}^{-1}$. This means that electron-phonon coupling is weak (with an estimated HuangRhys factor, $\mathrm{S}$ of $\sim 0.6$, assuming $\omega_{\mathrm{m}}$ of $17 \mathrm{~cm}^{-1}$ ). The fluorescence maximum of the D2-L209H mutant, in comparison to WT RCs, is blue shifted due to a different pigments contributing to the lowest-energy excitonic state. Recall that the absorption spectrum of the D2-L209H mutant, in which the active branch $\mathrm{Pheo}_{\mathrm{D} 1}$ is replaced with Chl $a$ (see inset of Figure 2), did not reveal (as expected) the $\mathrm{Q}_{\mathrm{x}}$-absorption band near $545 \mathrm{~nm}$ assigned to $\mathrm{Pheo}_{\mathrm{D} 1}$ (vide supra). In light of the above observations, it is interesting to note that the persistent (nonresonant) hole spectrum obtained for the mutant with $\lambda_{\mathrm{B}}=665.0 \mathrm{~nm}$ (curve $\mathrm{b}$ in Figure 4 ) has a $\sim 93 \mathrm{~cm}^{-1}$ wide hole centered at $\sim 680 \mathrm{~nm}$ but no response in the $Q_{x}$ pheophytin region (see inset below curve $b$ ), proving again that $\mathrm{Pheo}_{\mathrm{D} 2}$ does not contribute to the lowest-energy state near $680 \mathrm{~nm}$. The hole near $680 \mathrm{~nm}$ can be attributed to downward energy transfer from pigments excited at $665.0 \mathrm{~nm}$ to the (blue shifted) lowest-energy excitonic band in the mutant, which is strongly contributed to by Chls (in particular the $\mathrm{Chl} a$ residing in the $\mathrm{Pheo}_{\mathrm{D} 1}$ binding pocket and $\mathrm{Ch}_{\mathrm{D} 1}$ ). This is consistent with data shown in Figure 2, as the substituted Chl $a$ strongly contributes to the absorption spectrum near $680 \mathrm{~nm}$. As expected, WT RC samples intentionally degraded by leaving them on the bench at room temperature for many hours do not reveal any broad-band bleach near $680 \mathrm{~nm}$ in agreement with data shown in Figure S1 (see curves d) in Supporting Information. The identity of the pigment(s) contributing to the low-energy states of WT and mutant RCs will be discussed in section 4.3 . The weak ( $\sim 6 \%$ hole depth) symmetric transient hole (Figure 4 , curve c) 
is most likely formed via intersystem crossing and corresponds to the lowest-energy band ( $\sim 680$ $\mathrm{nm}$ ) of the mutant, although it cannot be excluded that the shallow transient hole reflects a triplet-bottleneck hole after recombination of the $\mathrm{Chl}_{\mathrm{D} 1}{ }^{+} \mathrm{Chla}^{-}$state (if formed). (Recall that $\mathrm{Chl}$ $a$ mentioned above resides in the Pheo ${ }_{\mathrm{D} 1}$ binding pocket). This suggestion needs to be tested via resonant $\mathrm{HB}$ and time resolved spectroscopies. Curve b, however, is asymmetric in the higher frequency range due to the presence of an anti-hole typically observed in persistent HB spectra. ${ }^{40,62}$ Nevertheless, these data clearly support our above assignment that the mean site energy of $\mathrm{Pheo}_{\mathrm{D} 2}$ is unlikely to lie anywhere close to $680 \mathrm{~nm}$ and dominate the lowest-energy excited state, as suggested in $\operatorname{Refs}^{29,38}$. We hasten to add that our findings also question the assignment of site energies of pheophytins obtained with the in vitro exchange experiments, where $P$ Pheo $\mathrm{D}_{\mathrm{D} 1}$ and/or Pheo $\mathrm{D}_{\mathrm{D} 2}$ were replaced by $13^{1}$-deoxo- $13^{1}$-hydroxy pheophytin $\left(13^{1}-\mathrm{OH}\right.$ Pheo). ${ }^{7,41}$ The observation reported in Refs ${ }^{7,41}$ that both $\mathrm{Pheo}_{\mathrm{D} 1}$ and Pheo $\mathrm{D}_{\mathrm{D} 2}$ contribute at the same wavelength to the absorption spectrum, both in the $\mathrm{Q}_{y^{-}}$and $\mathrm{Q}_{\mathrm{x}}$-regions, could indicate that exchange experiments destabilize RCs or perturb excitonic interactions. The observed bleach near $680 \mathrm{~nm}$ and the absorption increase at $\sim 654 \mathrm{~nm}$ (the $\mathrm{Q}_{\mathrm{y}}$-transition of replaced $13^{1}-\mathrm{OH}$ Pheo $^{7,41}$ ) are not necessarily correlated, i.e., some changes observed near $680 \mathrm{~nm}$ could be due to partial damage of RCs and the accompanying changes in the excitonic interactions. Therefore, in light of the data presented in this work, we cannot exclude the possibility that some delta absorbance changes (near $680 \mathrm{~nm}$ region) observed in samples going through the chemical exchange process and purification are induced by RC destabilization. In fact, difference spectra reported in Refs ${ }^{7,41}$ if not normalized at $624 \mathrm{~nm}$, would be similar to spectra c shown in Figure S1 for destabilized RCs in Supporting Information.

3.4. Monte Carlo simulations of the absorption difference spectra of C. reinhardtii and its D2-L209H mutant. The red curve (c) in Figure 2 corresponds to delta absorbance spectra 
obtained for WT RC and its mutant, assuming a dipole strength ratio of Pheo a/Chl a of 0.5. ${ }^{55}$ The green curve (spectrum d) in Figure 2 was obtained using excitonic calculations for the $\mathrm{Q}_{\mathrm{y}^{-}}$ states using the Frenkel Hamiltonian mentioned above. We used coupling constants calculated by the $a b$ initio TrEsp method ${ }^{11}$ and the recent X-ray structural data (3ARC PDB, file) ${ }^{1}$. The coupling constants (with the exception of the coupling constant $(V)$ for the special pair $V_{\text {PD1-PD2) }}$ were very similar to those reported in ${ }^{11}$ and are listed in Table S1 in the Supporting Information. Taking into account a considerable wavefunction overlap between $\mathrm{P}_{\mathrm{D} 1}$ and $\mathrm{P}_{\mathrm{D} 2}$ Chls, resulting in Dexter-type exchange coupling, the coupling constant $V_{\mathrm{PD} 1-\mathrm{PD} 2}$ of $150 \mathrm{~cm}^{-1}$ was taken from Ref. ${ }^{11}$ The site energies were adjusted using our experimental constraints obtained for the site energies of both $\mathrm{Pheo}_{\mathrm{D} 1}$ and of $\mathrm{Pheo}_{\mathrm{D} 2}$, as discussed above. The site energies used for $\mathrm{Pheo}_{\mathrm{D} 1}$ and $\mathrm{Pheo}_{\mathrm{D} 2}$ are $\sim 679.8$ and $\sim 670 \mathrm{~nm}$, respectively. The inhomogeneous width of $165 \mathrm{~cm}^{-1}$ was used in the Monte Carlo simulations. Absorption spectra of C. reinhardtii and its D2-L209H mutant were calculated with the same set of parameters with the only adjustment that Pheo ${ }_{\mathrm{D} 1}$ in WT RC was replaced with $\mathrm{Chl} a$ in the mutant, and the site energy of $\mathrm{Chl}$ a (residing in the Pheo ${ }_{\mathrm{D} 1}$ binding pocket) was shifted to the blue by $125 \mathrm{~cm}^{-1}$ from the site energy of Pheo $\mathrm{D}_{\mathrm{D} 1}$ at $14710 \mathrm{~cm}^{-1}(679.8$ $\mathrm{nm}$ ). This shift is consistent with the loss of H-bonding (with Glutamine 130) in Chl $a$ residing in the Pheo $\mathrm{D}_{\mathrm{D}}$ binding pocket. The nice agreement between experimental and calculated difference spectra in the low energy spectral range provides further evidence that $\mathrm{Pheo}_{\mathrm{D} 1}$ in WT RC significantly contributes to the lowest energy exciton state near $684 \mathrm{~nm}$ and has a site energy near $680 \mathrm{~nm}$ (see section 4.3 for more details).

\section{Discussion}

4.1. Nonresonant persistent holes. Historically, the original assignment of the broad $\left(\sim 120 \mathrm{~cm}^{-1}\right)$ nonresonant persistent hole, typically observed near $680-682 \mathrm{~nm}^{25,26,61}$ for $665 \mathrm{~nm}$ 
excitation in isolated RCs from spinach, was to a $\mathrm{Q}_{\mathrm{y}}$-state localized on Pheo ${ }_{\mathrm{D} 1}{ }^{25}$ This was proposed prior to the introduction of the multimer model..$^{34,63,64}$ Subsequent research revealed that only nonresonant excitation near $660-670 \mathrm{~nm}$ reveals persistent bleaching at the $\mathrm{Q}_{\mathrm{x}}$ band assigned to $\mathrm{PheO}_{\mathrm{D} 1}{ }^{25}$ meaning that the $\mathrm{Q}_{\mathrm{x}}$ bleach is never observed for saturated holes burned resonantly in the $680-686 \mathrm{~nm}$ region. In Ref. ${ }^{4}$ we provided evidence for highly dispersive primary charge separation kinetics; that is, we have shown that population of either P680* (in RC680, where * $\equiv$ the $\mathrm{Q}_{\mathrm{y}}$-state) or P684* (in RC684, the subset of RCs more intact than RC680) results in both resonant transient (due to charge recombination of the primary radical pair) and resonant persistent (nonphotochemical) holes. Indeed, one set of parameters (e.g. electronphonon coupling and site distribution function) could be used to simulate all transient and persistent holes burned in the $680-686 \mathrm{~nm}$ region. Thus the question arises what is the origin of the broad nonresonant $\sim 680$ and $\sim 684 \mathrm{~nm}$ persistent holes (as shown in Figure 3, frames $\mathrm{C}$ and D) accompanied by a clear bleach in the $\mathrm{Q}_{\mathrm{x}}$-region of $\mathrm{Pheo}_{\mathrm{D} 1}$ ?

We suggest that our original interpretation, ${ }^{25}$ namely that this broad hole belongs to the quasi-localized $\mathrm{Q}_{\mathrm{y}}$-band of Pheo $\mathrm{D}_{\mathrm{D} 1}$ may actually be correct. We propose that these non-resonant persistent $\mathrm{HB}$ spectra could be formed (via $\mathrm{CW}$ excitation) during the relatively long lifetime ( $\sim 2$ $\mathrm{ms}^{9,65}$ ) of the ${ }^{3} \mathrm{P} 680$ or ${ }^{3} \mathrm{P} 684$ triplet states that are formed (in the absence of $\mathrm{Q}_{\mathrm{A}}$ ) after recombination of the $\mathrm{P} 680^{+} \mathrm{Pheo}_{\mathrm{D} 1}{ }^{-}$and $\mathrm{P} 684^{+} \mathrm{Pheo}_{\mathrm{D} 1}{ }^{-}$states, respectively. In these cases, the formation of ${ }^{3} \mathrm{P} 680$ or ${ }^{3} \mathrm{P} 684$ (if the triplet is localized on $\mathrm{Chl}_{\mathrm{D} 1}{ }^{13}$ ) could partially decouple $\mathrm{Pheo}_{\mathrm{D} 1}$ from the rest of the $\mathrm{RC}$ pigments. If Pheo ${ }_{\mathrm{D} 1}$ has a site energy of $\sim 680 \mathrm{~nm}$, as suggested in this work, it would contribute to the energy trap for EET from states at $\sim 665 \mathrm{~nm}$ which are excited by the laser. This indeed could lead to weak broad $\left(\sim 120 \mathrm{~cm}^{-1}\right)$ satellite holes with hole minima near $680 \mathrm{~nm}$ and/or $684 \mathrm{~nm}$, depending on the quality (i.e., intactness) of the RC 
sample. ${ }^{25,26,61}$ Note that the same process is highly improbable in the case of resonant burning. The RCs, which are resonantly excited at 680-684 nm, may exhibit either slow or fast primary charge separation ${ }^{5}$, with persistent HB favoring slow charge separation RCs very strongly (i.e., RCs with fast charge separation and likely triplet formation do not contribute much). On the other hand, in RCs exhibiting fast charge separation the NPHB into the original lowest-energy state should be very inefficient based on the equation for the spectral hole burning yield ${ }^{39}$ :

$$
\phi_{S H B}=\frac{\Omega_{0} e^{-2 \lambda}}{\Omega_{0} e^{-2 \lambda}+\tau_{C S}{ }^{-1}+\tau_{f l}{ }^{-1}},
$$

where $\Omega_{0} e^{-2 \lambda}$ is the NPHB rate, and $\tau_{c s}$ and $\tau_{f l}$ are the charge separation time and fluorescence lifetime, respectively. Then during the lifetime of the ${ }^{3} \mathrm{P} 680$ - or ${ }^{3} \mathrm{P} 684$-triplet states, the narrow zero-phonon lines (ZPL) of the lowest state (now localized on $\mathrm{Pheo}_{\mathrm{D} 1}$ ) would not be in resonance with the laser, and, as a result, these RCs will become unavailable for further absorption of resonant photons and NPHB. This escape of the lowest-energy state from the resonance with the laser due to triplet formation is obviously irrelevant for nonresonant excitation at $665 \mathrm{~nm}$, as EET would occur anyway.

The only difference between (nonresonant) saturated persistent holes (quasi-localized on Pheo $_{\mathrm{D} 1}$ ) burned with $\lambda_{\mathrm{B}}=665 \mathrm{~nm}$ (during the ${ }^{3} \mathrm{P} 680$ and ${ }^{3} \mathrm{P} 684$ triplets, in RC680 and RC684, respectively) is that the corresponding $\mathrm{Q}_{\mathrm{x}}-\mathrm{Q}_{\mathrm{y}}$-transitions depending on sample intactness are at $\sim 544 \pm 1 / \sim 680.6 \mathrm{~nm}$ and $\sim 545 \pm 1 / 683.8 \mathrm{~nm}$, respectively, as further discussed in the Supporting Information. This is why $\mathrm{Q}_{\mathrm{y}^{-}}$nonresonant persistent holes have a profile similar to that obtained due to formation (in the presence of dithionite) of stable Pheo ${ }_{\mathrm{D} 1}{ }^{-26,34}$ However, the situation is more complicated in intact RC684 from C. reinhardtti, which could contain plastoquinone $\mathrm{Q}_{\mathrm{A}}$, and possibly possess two electron donors, $\mathrm{P}_{\mathrm{D} 1}$ and/or $\mathrm{Ch} \mathrm{D}_{\mathrm{D} 1}$ (i.e., two charge separation pathways, as recently proposed in $\mathrm{Ref}^{5}$ ). That is, the transient hole in Figure $3 \mathrm{E}$ may have 
contributions from both the ${ }^{3} \mathrm{P} 684$ triplet and the long-lived $\mathrm{P}^{+} \mathrm{Q}_{\mathrm{A}}{ }^{-}$state ${ }^{66}$ for a subpopulation of RCs that contain $\mathrm{Q}_{\mathrm{A}}$. The nature of the electron donor(s) and the feasibility of multiple electron transfer pathways in C. reinhardtii (including measurements of electron transfer times via resonant $\mathrm{HB}$ ) is discussed $\mathrm{in}^{49}$. Here we only note that the ratio of the nonresonant TBHB spectrum $(\mathrm{I}=100 \mathrm{~mW}$ ) to NPHB (saturated persistent hole) in spinach (see Figure 3 ) is about 3.5, while the same ratio in C. reinhardtii (obtained under identical conditions; see Figure 3) is about 5.5. Interestingly, the ratio of $\sim 3.6$ was also observed in destabilized P680-type RCs obtained for $C$. reinhardtii. Since the depth of the saturated persistent hole (nonresonant, $\lambda_{\mathrm{B}}=$ $665.0 \mathrm{~nm}$, obtained under similar conditions) in: (1) spinach RC near $\sim 680 \mathrm{~nm}$; (2) destabilized $\mathrm{RC}$ from C. reinhardtii (also at $\sim 680 \mathrm{~nm}$; data not shown); and (3) intact $\mathrm{RC}$ from C. reinhardtii $(\sim 683.8 \mathrm{~nm})$, is only $\sim 3-4 \%$, it is not surprising that the persistent (nonresonant) hole from a small subset of intact P684-type RCs near $684 \mathrm{~nm}$ in spinach RCs (revealed as a weak shoulder near $684 \mathrm{~nm}$ in a transient hole ${ }^{61}$ ) has been never observed.

4.2. Site energies of $\mathbf{P h e o}_{\mathrm{D} 1}$ and $\mathbf{P h e o}_{\mathrm{D2}}$. We emphasize that knowledge of the site energies of the Chls and Pheos is important to understand the excitonic structure and excitation energy transfer in PSII RCs, as they determine the direction of the energy flow. Recall that conclusions made from the experiments with borohydride reduction of the inactive branch Pheo $_{\mathrm{D} 2}{ }^{67}$ and exchange of $\mathrm{Pheo}_{\mathrm{D} 2}{ }^{7,41,68}$, as well as with partial exchange of Pheo ${ }_{\mathrm{D} 1}{ }^{7,41}$ with $13^{1}$ hydroxy Pheo (vide supra) ${ }^{7,41}$, which suggested that both pheophytins have their $\mathrm{Q}_{\mathrm{y}}$ absorption maxima at 676-680 $\mathrm{nm}$ (at $6 \mathrm{~K}$ ), are inconsistent with data shown above. In addition, the blue shift of both the $\mathrm{Q}_{\mathrm{x}}$ and $\mathrm{Q}_{\mathrm{y}}$ transitions of $\mathrm{Pheo}_{\mathrm{D} 1}$ in destabilized RCs (see Figure S1; Supporting Information) is consistent with resonance Raman spectroscopy data ${ }^{69}$, where it was suggested that $\mathrm{Pheo}_{\mathrm{D} 1}$ in the PSII RC is likely H-bonded (as $\mathrm{BPheo}_{\mathrm{L}}$ in the $\mathrm{BRC}^{70,71}$ ), with the glutamine 
residue D1-Gln130 being the likely homologue of the glutamic acid residue L-104 in BRC. That is, in the Synechocystis site-directed mutation, D1-Gln130Leu results in the shifting of the $\mathrm{Q}_{\mathrm{x}}$ band to shorter wavelength consistent with a disappearance of the $\mathrm{C} 13^{1}=\mathrm{O}$ hydrogen bond. Different $\mathrm{Q}_{\mathrm{x}}$ and $\mathrm{Q}_{\mathrm{y}}$ positions of Pheo ${ }_{\mathrm{D} 1}$ and Pheo $\mathrm{D}_{\mathrm{D} 2}$ also suggest that only Pheo $\mathrm{D}_{\mathrm{D} 1}$ is H-bonded ${ }^{72}$. Thus we suggest that the H-bond of Pheo $\mathrm{D}_{1}$ can be easily broken in destabilized RCs, as shown by the blue shift of the $\mathrm{Q}_{\mathrm{y}}$-absorption band in Figure S1 (see Supporting Information). Finally, the different $\mathrm{Q}_{\mathrm{y}}$ positions of Pheo $\mathrm{D}_{\mathrm{D} 1}$ and $\mathrm{Pheo}_{\mathrm{D} 2}$ are consistent with an earlier suggestion in Ref. ${ }^{69}$ that one possible distinction between the active and inactive branches of the PSII RC might be the presence of a H-bonded pheophytin on the active branch and the absence of a hydrogen bond on the inactive branch. The latter is consistent with data presented above, but contradicts the conclusions reached in ${ }^{72}$ that the $\mathrm{Q}_{\mathrm{x}}$ transitions of both pheophytins located at $543 \mathrm{~nm}$ imply that both pheophytins have a $\mathrm{H}$-bond to the $\mathrm{C}_{13}{ }^{1}=\mathrm{O}$ of equal strength. Other groups also concluded that the Pheo $\mathrm{D}_{1}$ contributes to the low-energy state near $681 \mathrm{~nm} \cdot{ }^{3,37,42,73-75}$ Several earlier studies also indicated that the site-energy of Pheo ${ }_{\mathrm{D} 2} \mathrm{Q}_{\mathrm{y}}$-state must be located near $668-672 \mathrm{~nm}^{26,34,37,73-}$ ${ }^{75}$, in agreement with the results presented in this paper.

4.3. Excitonic calculations. In calculations of absorption spectra (and of the difference spectrum shown in Figure 2 (curve d)), inhomogeneous broadening $\left(\Gamma_{\text {inh }}=165 \mathrm{~cm}^{-1}\right)$ was treated via Monte Carlo methods, while homogenous broadening was included by convoluting the calculated spectra with an assumed single site (SSA) spectrum for absorption. The parameters used for the SSA curve (i.e., zero phonon line width $=0.5 \mathrm{~cm}^{-1}, \mathrm{~S}=0.8, \omega_{\mathrm{m}}=17 \mathrm{~cm}^{-1}$ ) were taken from ${ }^{4}$. Vibrational modes of $\mathrm{Chl} a$ were adopted from ${ }^{76}$. The other common property of the parameter sets resulting in good fits to the difference spectrum shown in Figure 2 is that the site energy of Pheo ${ }_{\mathrm{D} 2}$ used in the modeling was near $670 \mathrm{~nm}$. In addition, our modeling data confirm 
that the site energies of $\mathrm{P}_{\mathrm{D} 1}$ and $\mathrm{P}_{\mathrm{D} 2}$ found by Renger's group ${ }^{11,29}$ are correct and must lie in the 665-667 $\mathrm{nm}$ region. We also confirm that the $\mathrm{Chl}_{\mathrm{D} 1}$ site energy must be red shifted to about 678 $\mathrm{nm}$ in agreement with Ref. $^{29}$ and various calculations of triplet-bottleneck spectra. ${ }^{11}$ Discussion of site energies for PSII RCs, along with simultaneous fits of WT and mutant RC absorption, emission, triplet-bottleneck holes, and transient $\mathrm{P}_{\mathrm{D} 1}{ }^{+} \mathrm{Q}_{\mathrm{A}}{ }^{-}-\mathrm{P}_{\mathrm{D} 1} \mathrm{Q}_{\mathrm{A}}$ spectra will be reported elsewhere as fits of absorption spectra alone cannot provide the final set of site energies. Nevertheless, all pigment site energies tested so far, which can simultaneously describe the absorption spectra of WT RC and its D2-L209H mutant, as well as their difference shown in Figure 2, have in common that the site energy of Pheo ${ }_{\mathrm{D} 1}$ must be near $679-681 \mathrm{~nm}$, in agreement with our experimental data reported above, and previously published results. ${ }^{3,26,34,37,42,73-75}$

4.4. Transient holes. The transient spectrum obtained for isolated RC from C. reinhardtti (frame C, Figure 3) is very similar to the flash-induced $\left(\mathrm{P}_{684}{ }^{+} \mathrm{Q}_{\mathrm{A}}{ }^{-}-\mathrm{P} 64 \mathrm{Q}_{\mathrm{A}}\right)$ absorbance difference spectra of PSII core complexes from WT Synechocystis sp. PCC $6803 .{ }^{13}$ The latter suggests the presence of $\mathrm{Q}_{\mathrm{A}}$; therefore, an electrochromic shift in the $\mathrm{Q}_{\mathrm{x}}$-region of the pheophytins is possibly due to the formation of the $\mathrm{P}^{+} \mathrm{Q}_{\mathrm{A}}{ }^{-}$state, as previously observed in bacterial RCs ${ }^{60,77,78}$ and PSII cores. ${ }^{14,58,59}$ As expected, there was no bleach or shift in the 530$560 \mathrm{~nm}$ region in the $\mathrm{D} 2-\mathrm{L} 209 \mathrm{H}$ mutant, since there is no formation of a $\mathrm{P}^{+} \mathrm{Q}_{\mathrm{A}}{ }^{-}$state, even if $\mathrm{Q}_{\mathrm{A}}$ is present, due to the lack of active Pheo $\mathrm{D}_{\mathrm{D}}$. This proves that our isolated $\mathrm{RCs}$ from C. reinhardtti are to a large extent intact with a bleach at $672.7 \mathrm{~nm}$ being due to the oxidation of $\mathrm{P}$ (mostlikely $\mathrm{P}_{\mathrm{D} 1}$ ), or, expressed more properly and as discussed by Schlodder et al. in the case of PSII core from Synechocystis ${ }^{13}$, due to the bleaching of an exciton state dominated by contributions from $\mathrm{P}_{\mathrm{D} 1}$. This is consistent with recent finding that the redox potential $\left(\mathrm{E}_{\mathrm{m}}\right)$ of $\mathrm{P}_{\mathrm{D} 1}$ for a one-electron oxidation $\left(\mathrm{E}_{\mathrm{m}}\left(\mathrm{P}_{\mathrm{D} 1}\right)\right)$ is lower than that of $\mathrm{P}_{\mathrm{D} 2}$, favoring localization of the cationic charge state 
more on $\mathrm{P}_{\mathrm{D} 1}{ }^{79}$ The positive peak in the transient spectrum (see frame $\mathrm{E}$ in Figure 3 ) is related to an electrochromic shift of the pigment(s) contributing to the lowest-energy state (most likely $\mathrm{Chl}_{\mathrm{D} 1}$ and $\left.\mathrm{PheO} \mathrm{D}_{1}\right)$, induced by the positive charge on $\mathrm{P}\left(\mathrm{P}_{\mathrm{D} 1}{ }^{12,13,79}\right)$ and a negative charge on plastoquinone $\mathrm{Q}_{\mathrm{A}}\left(\mathrm{Q}_{\mathrm{A}}{ }^{-}\right)$. A very different shape of the transient hole observed in spinach $\mathrm{RC}$ (frame F) is most likely the result of disruptive protein-pigment structural perturbations introduced by the isolation procedure and absence of $\mathrm{Q}_{\mathrm{A}}$. We suggest that in spinach $\mathrm{RCs}$ (see frame F) $\mathrm{Chl}_{\mathrm{D} 1}$ is the preferred electron donor with the triplet also localized on $\mathrm{Ch}_{\mathrm{D} 1}{ }^{13,80 \text {, The }}$ lack of response near $672.7 \mathrm{~nm}$ in spinach RCs supports the notion that RC680 (in contrast to RC684) has destabilized D1 and D2 proteins with a significantly weakened excitonic coupling between the $\mathrm{P}_{\mathrm{D} 1}$ and $\mathrm{P}_{\mathrm{D} 2}$ Chls, and as a result, a much weaker absorption band near $673 \mathrm{~nm}$.

\section{Conclusions.}

A large number of isolated RC preparations from spinach and wild-type C. reinhardtii (at different levels of intactness), as well as the D2-L209H mutant, in which the active branch Pheo $_{\mathrm{D} 1}$ has been genetically replaced with $\mathrm{Chl} a$, have been studied by HB spectroscopy. This work provides direct evidence that the biochemical treatment used to isolate D1-D2-Cytb $559 \mathrm{RC}$ complex may change optical properties of the RC pigments. It appears, however, that RCs with similar properties to those observed in intact PSII cores can be obtained; the latter is of critical importance, as optical spectra of PSII cores are more difficult to interpret due to possible contributions from CP43 and CP47 antenna pigment complexes. The results presented here offer no support for the recent assignments ${ }^{11,14,29,38}$ that site energies of $P$ Pheo $\mathrm{D}_{\mathrm{D} 1}$ and $\mathrm{PheO} \mathrm{D}_{\mathrm{D} 2}$ are at 672 $\mathrm{nm}$ and $677.5 \mathrm{~nm}$, respectively. It is also unlikely that both pheophytins contribute to the absorption near 676-681 nm region as proposed in Refs. ${ }^{7,33,41,42}$ In contrast, we have demonstrated that the $\mathrm{Q}_{\mathrm{x}}-\mathrm{Q}_{\mathrm{y}}$-region site-energies of $\mathrm{Pheo}_{\mathrm{D} 1}$ and $\mathrm{Pheo}_{\mathrm{D} 2}$ are most likely at $\sim 545 / \sim 680 \mathrm{~nm}$ and $\sim 541.5 / \sim 670 \mathrm{~nm}$, respectively, in good agreement with our previous 
assignment. ${ }^{26,34}$ These values should be used to model excitonic structure and excitation energy transfer dynamics of the PSII RC. We also propose that the nonphotochemical (nonresonant) persistent holes at $\sim 680$ and $\sim 684 \mathrm{~nm}$ (depending on the sample intactness), obtained via higherenergy excitation (e.g., $\lambda_{\mathrm{B}}=665.0 \mathrm{~nm}$ ) are, at least in part, the result of burning in the decoupled Pheo $_{\mathrm{D} 1} \mathrm{Q}_{\mathrm{y}}$-state during the lifetime of the long lived ${ }^{3} \mathrm{Ch} \mathrm{D}_{\mathrm{D} 1}$ triplet bottleneck-state in $\mathrm{RCs}$ without $\mathrm{Q}_{\mathrm{A}}$. On the other hand, the narrow (lifetime limited) resonant holes ${ }^{23,81}$ as well as the saturated resonant holes burned in the 678-686 nm spectral region of the PSII RC (with no bleaching in the $\mathrm{Q}_{\mathrm{x}}$ band of the pheophytins) are not bleached in the $\mathrm{Pheo}_{\mathrm{D} 2}$ dominated lowenergy exciton band, as suggested in ${ }^{11,29,38}$. On the contrary, the experimentally observed distribution of hole widths in both persistent and transient HB spectra ${ }^{4,39,82}$ must be associated with highly dispersive primary charge separation kinetics in destabilized RC680 and intact RC684.

\section{Acknowledgements}

Spectroscopic and modeling studies of RCs were supported by the NSF ARRA Grant (CHE090795) to R.J. Partial support to B.N. (involved in calculations) was provided by the NSF EPSCoR Grant. V.Z. (involved in writing the manuscript) acknowledges support by NSERC. R.T.S., R.P., and M.S. were involved in the design and preparation of D2-mutant and RCs. They acknowledge support from USDOE, Photosynthetic Antennae Research Center (R.T.S.), MICIN (Grant AGL2008-00377) in Spain (R.P.), and the U.S. Department of Energy's Photosynthetic Systems Program within the Chemical Sciences, Geosciences, and Biosciences Division of the 
Office of Basic Energy Sciences under NREL Contract \#DE-AC36-08-GO28308 (M.S.). R.J. thanks M. Reppert (MIT) for insightful discussion and comments.

Supporting Information Available: This material contains information on spectroscopic measurements of destabilized RCs as well as the coupling constants used for the excitonic calculation. This material is available free of charge via the Internet at http://pubs.acs.org.

\section{Figure captions}

Figure 1. Cofactor arrangement in the active (D1) and inactive (D2) branches of the PSII RC based on the crystal structure of T. vulcanus at $1.9 \AA$ resolution, PDB ID $3 \mathrm{ARC}^{1}$. The left frame shows the arrangement in WT RCs (chls, green; carotenes, yellow; pheophytins, purple; plastoquinones, gray; non-heme iron, red; and nitrogen, blue). The right frame shows the arrangement of selected pigments and their ligands (water, orange; histidine, red; leucine, cyan) in the D2-L209H RC mutant. The substituents of the cofactors are truncated for clarity.

Figure 2. Spectra a and b correspond to the absorption spectra of intact WT and D2-L209H mutant RCs, respectively, measured at $\mathrm{T}=5 \mathrm{~K}$. The areas of curve $\mathrm{a}$ and $\mathrm{b}$ are scaled to 7.0 and 7.5, respectively, based on the normalized oscillator strength of the cofactors. Curve $\mathrm{c}$ is the difference between spectra $b$ and $a$, and curve $d$ is the calculated difference spectrum. The inset shows the corresponding $Q_{x}$-region (see text for detail). 
Figure 3. Absorption, nonresonant persistent hole, and transient $\mathrm{HB}$ spectra obtained for RCs from $C$. reinhardtii and spinach $\mathrm{RC}$ are shown in frames $\mathrm{A} / \mathrm{C} / \mathrm{E}$ and $\mathrm{B} / \mathrm{D} / \mathrm{F}$, respectively. The insets in frames $\mathrm{A}$ and $\mathrm{B}$ show the $\mathrm{Q}_{\mathrm{x}}$ absorption band of both pheophytins near 544 and $543 \mathrm{~nm}$, while those in frames $\mathrm{E}$ and $\mathrm{F}$ illustrate the $\mathrm{Q}_{\mathrm{x}}$ response (in the pheophytin region) in the transient spectra. All HB spectra were obtained with a $\lambda_{\mathrm{B}}$ of $665 \mathrm{~nm}$ and were measured at $5 \mathrm{~K}$. The inset in frame $\mathrm{D}(\sim 544 \mathrm{~nm})$ corresponds to $\mathrm{Q}_{\mathrm{x}}$ bleach of Pheo $\mathrm{D}_{1}$ (see text).

Figure 4. Curves a, a', b, and c correspond to the absorption, fluorescence, persistent, and transient HB spectra obtained for the D2-L209H mutant of C. reinhardtii. Both HB spectra were obtained with a $\lambda_{\mathrm{B}}$ of $665.0 \mathrm{~nm}$, and recorded at $5 \mathrm{~K}$. The inset below curve b shows that there is no bleaching in the $\mathrm{Q}_{\mathrm{x}}$-region of Pheo ${ }_{\mathrm{D} 2}$ (note, $\mathrm{Pheo}_{\mathrm{D} 1}$ is absent in D2-mutant).

\section{References}

(1) Umena, Y.; Kawakami, K.; Shen, J.-R.; Kamiya, N. Nature 2011, 473, 55-60.

(2) Deisenhofer, J.; Epp, O.; Miki, K.; Huber, R.; Michel, H. Nature 1985, 318, 618-624.

(3) Nanba, O.; Satoh, N.; Proc. Natl. Acad. Sci. U. S. A. 1987, 84, 109-122.

(4) Riley, K. J.; Jankowiak, R.; Rätsep, M.; Small, G. J., Zazubovich, V. J. Phys. Chem. B 2004, $108,10346-10356$.

(5) Romero, E.; van Stokkum , I. H.; Novoderezhkin, V. I.; Dekker, J. P.; van Grondelle, R. Biochem. 2010, 49, 4300-4307.

(6) Prokhorenko, V. I.; Holzwarth, A. R. J. Phys. Chem. B 2000, 104, 11563-11578. 
(7) Germano, M.; Shkuropatov, A. Ya.; Permentier, H.; de Wijn, R.; Hoff, A. J.; Shuvalov, V. A.; van Gorkom, H. J. Biochem. 2001, 40, 11472-11482.

(8) Germano, M.; Gradinaru, C. C.; Shkuropatov, A. Ya.; van Stokkum, I. H. M.; Shuvalov, V. A.; Dekker, J. P.; van Grondelle, R.; van Gorkom, H. J. Biophys. J. 2004, 86, 1164-1672.

(9) Groot, M.-L.; Peterman, E. J. G.; van Kam, P. J. M.; van Stokkum, I. H. M.; Dekker, J. P.; van Grondelle, R. Biophys. J. 1994, 67, 318-330.

(10) Xiong, L.; Seibert, M.; Gusev, A. V.; Wasielewski, M. R.; Hemann, C.; Hille, C. R; Sayre, R. T. J. Phys. Chem. B 2004, 108, 16904-16911.

(11) Raszewski, G.; Diner. B. A.; Schlodder, E.; Renger, T. Biophys. J. 2008, 95, 105-119.

(12) Diner, B. A.; Schlodder, E.; Nixon, P. J.; Coleman, W. J.; Rappaport, F.; Levergne, J.;

Vermaas, W.F. J.; Chisholm, D. A. Biochem. 2001, 40, 9265-9281.

(13) Schlodder, E.; Coleman, W. J.; Nixon, P. J.; Cohen, R. O.; Renger, T.; Diner, B. A. Phil. Trans. R. Soc. B 2008, 363, 1197-1202.

(14) Cox, N.; Hughes, J. L.; Steffen, R.; Smith, P. J.; Rutherford, W.; Pace, R. J.; Krausz, E. J. Phys. Chem. B 2009, 113, 12364-12374.

(15) Andronis, C.; Merry, S.A.P.; Durrant, J.; R.; Klug, D. R.; Barber, J.; Nixon, P. J. Photosynth. Res. 1999, 62, 205-217.

(16) Alizadeh, S.; Nixon, P. J.; Telfer, A.; Barber, J.; Photosynth. Res. 1995, 43, 165-171.

(17) Xiong, J.; Subramanian, S.; Govindjee Photosynth. Res. 1998, 56, 229-254.

(18) Wang, J.; Gosztola, D.; Ruffle, S. V.; Hemann, C.; Seibert, M.; Wasielewski, M. R.; Hille, R.; Gustafson, T. L.; Sayre, R. T. Proc. Natl. Acad. Sci. U. S. A. 2002, 99, 4091-4096. 
(19) Shelaev, I. V.; Gostev, F. E.; Nadtochenko, V. A.; Shkuropatov, A. Ya.; Zabelin, A. A.;

Mamedov, M. D.; Semenov, A. Yu.; Sarkisov, O. M.; Shuvalov, V. A. Photosynth. Res. 2008, 98, 95-103.

(20) Holzwarth, A. R.; Müller, M.; Reus, M.; Nowaczyk, M.; Sander, J.; Rögner, M. Proc. Natl. Acad. Sci. U. S. A. 2006, 103, 6895-6900.

(21) Myers, J. A.; Lewis, K. L. M.; Fuller, F. D.; Tekavec, P. F.; Yocum, C. F.; Ogilvie, J. P. J. Phys. Chem. Lett. 2010, 1, 2774-2780.

(22) Abramavicius, D.; Mukamel, S. J. Chem. Phys. 2010, 113, 184501-1:184501-13.

(23) den Hartog, F. T. H.; Vascha, F.; Lock, A. J.; Barber, J.; Dekker, J. P.; Völker, S. J. Phys. Chem. B. 1998, 102, 9174-9180.

(24) Dědic, R.; Lovčinskŷ, M.; Vácha, F.; Hala, J. J. Lumin. 2000, 87-89, 809-811.

(25) Tang, D.; Jankowiak, R.; Seibert, M.; Yocum, C. F.; Small, G. J. J. Phys. Chem. 1990 24, $6519-6522$.

(26) Jankowiak, R.; Rätsep, M.; Picorel, R.; Seibert, M.; Small, G. J. J. Phys. Chem. B 1999, 103, 9759-9769.

(27) Zazubovich, V.; Jankowiak, R.; Riley, K.; Picorel, R.; Seibert, M.; Small, G. J. J. Phys. Chem. B 2003, 107, 2862-2866.

(28) Jankowiak, R.; Rätsep, M.; Hayes, J.; Zazubovich, V.; Picorel, R.; Seibert, M.; Small, G. J. J. Phys. Chem. B 2003, 107, 2068-2074.

(29) Raszewski, G.; Saenger, W.; Renger, T. Biophys. J. 2005, 88, 986-998.

(30) Madjet, M. E.; Abdurahman, A.; Renger, T. J. Phys. Chem. B 2006, 110,17268-17281.

(31) Novoderezhkin, V. I.; Dekker, J. P; van Grondelle, R. Biophys. J. 2007, 93, 1293-1311. 
(32) Novoderezhkin, V. I.; Romero, E.; Dekker, J. P.; van Grondelle, R. ChemPhysChem 2011, 12, 681-688.

(33) Saito K, Mukai, K.; Sumi, H. Chem. Phys. Lett. 2005, 401, 122-129.

(34) Jankowiak, R.; Hayes, J. M.; Small, G. J. J. Phys. Chem. B 2002, 106, 8803-8814.

(35) Reppert, M.; Zazubovich, V.; Dang, N. C.; Seibert, M.; Jankowiak, R. J. Phys. Chem. B 2008, 112, 9934-9947.

(36) Reppert, M.; Acharya, K.; Neupane, B.; Jankowiak, R. J. Phys. Chem. B 2010, 114, 1188411898.

(37) Vasil'ev, S.; Orth, P.; Zouni, A.; Owens, T. G.; Bruce, D. Proc. Natl. Acad. U. S. A. 2001, $98,8602-8807$.

(38) Cox, N.; Hughes, J.; Rutherford, A.W.; Krausz, E. Physics Procedia 2010, 3, 1601-1605.

(39) Herascu, N.; Ahmouda, S.; Picorel, R.; Seibert, M.; Jankowiak, R.; Zazubovich, V. J. Phys. Chem. B. 2011, 115, 15098-15109.

(40) Jankowiak, R.; Reppert, M.; Zazubovich, V.; Pieper, J.; Reinot, T. Chem. Rev. 2011, 111, $4546-4598$.

(41) Germano, M.; Shkuropatov, A. Ya.; Permentier, H.; Khatypov, R. A.; Shuvalov, V. A.; Hoff, A. J.; van Gorkom, H. J. Photosynth. Res. 2000, 64, 189-198.

(42) Yruela, I.; Torrado, E.; Roncel, M.; Picorel, R. Photochem. Photobiol. 2001, 67, 199-206.

(43) Xiong, L. Modification of the Protein Matrix around Active- and Inactive Pheophytins by Site-Directed Mutagenesis, Affects on Energy And Electron Transfer Processes in Photosystem II. Ph. D. Dissertation, The Ohio State University, Columbus, Ohio, 2002.

(44) Kálmán, L.; Williams, J. C.; Allen, J. P. Photosynth. Res. 2008, 98, 643-655.

(45) Kirmaier, C.; Gaul, D.; DeBey, R.; Holten, D.; Schenck, C. C. Science 1991, 251, 922-927. 
(46) Heller, B. A.; Holten, D., Kirmaier, C. Science 1995, 269, 940-945.

(47) Chirino A. J.; Lous, E. J.; Huber, M.; Allen, J. P.; Schenck, C. C.; Paddock, M. L.; Feher, G.; Ress, D. C. Biochem. 1994, 33, 4584-4593.

(48) Gall, B.; Zehetner, A.; Scheer, H. FEBS Lett. 1998, 434, 88-92.

(49) Acharya, K.; Zazubovich, V.; Reppert, M.; Jankowiak, R. J. Am. Chem. Soc. 2012 (submitted)

(50) Mimuro, M.; Tomo, T.; Nishimura, Y.; Yamazaki, I.; Satoh, K. Biochim. Biophys. Acta 1995, 1232,81-88.

(51) Vacha, F., Joseph, D. M., Durrant, J. R., Telfer, A., Klug, D. R., Porter, G., Barber, J. Proc. Natl. Acad. Sci. U. S.A. 1995, 92, 2929-2933

(52) Eijckelhoff, C.; Dekker, J. P. Photosynth. Res. 1997, 52, 69-73

(53) Dang, N. C.; Zazubovich, V.; Reppert, M.; Neupane, B.; Picorel, R.; Seibert, M.;

Jankowiak, R. J. Phys. Chem. B 2008, 112, 9921-9933.

(54) Neupane, B; Dang, N. C.; Acharya, K.; Reppert, M.; Zazubovich, V.; Picorel, R.; Seibert, M.; Jankowiak, R. J. Am. Chem. Soc. 2010, 132, 4214-4229.

(55) Årsköld, S. P.; Masters, V. M.; Prince, B. J.; Smith, P. J.; Pace, R. J.; Krausz, E. J. Am. Chem. Soc. 2003, 125, 13063-13074.

(56) Pearlstein, R. M. In Photosynthesis: Energy Conversion by Plants and Bacteria; Ed., Govindjee ; Academic press: New York, 1982; Vol. 1, pp. 293-330.

(57) Housssier, C.; Sauer, K.; J. Am. Chem. Soc. 1970, 92, 779-791

(58) Krausz, E.; Hughes, J. L.; Smith, P.; Pace, R.; Årsköld, S. P. Photochem. Photobiol. Sci. 2005, 4, 744-753.

(59) Hughes, J. L.; Smith, P.; Pace, R.; Krausz, E. Biochim. Biophys. Acta 2006, 1757, 841-851. 
(60) Jankowiak, R.; Small, G. J. In The Photosynthetic Reaction Centers; Eds. Norris J. and Deisenhofer J.; Academic Press: New York,1993; p133.

(61) Chang, H.-C.; Jankowiak, R.; Reddy, N. R. S.; Yocum, C. F.; Picorel, R.; Seibert, M., Small, G. J. J. Phys. Chem. 1994, 98, 7725-7735.

(62) Jankowiak, R.; Hayes, J. M.; Small, G. J. Chem. Rev 1993, 93, 1471-1502.

(63) Durrant, J. R.; Klug, D. R.; Kwa, S. L. S.; van Grondelle, R.; Porter, G.; Dekker, J. P. Proc. Natl. Acad. Sci. U. S. A. 1995, 92, 4798-4802.

(64) Tetenkin, V. L.; Gulyaev, B. A.; Seibert, M.; Rubin, A. B. FEBS Lett. 1989, 250, 459-463. (65) van Kan, P. J. M.; Otte, S. C. M.; Kleinherenbrink, F. A. M.; Nieveen, M. C.; Aartsma, T. J.; van Gorkom, H. J. Biochim. Biophys. Acta. 1990, 1020, 146-152.

(66) van Mieghem, F.; Brettel, K.; Hillmann, B.; Kamlowski, A.; Rutherford, A. W.; Schlodder, E. Biochem. 1995, 34, 4798-4813.

(67) Shkuropatov, A. Y.; Khatypov, R. A.; Volshchukova, T. S.; Shkuropatova, V. A.; Owens, T. G.; Shuvalov, V. A. FEBS Lett. 1997, 420, 171-174.

(68) Shkuropatov, A. Y.; Khatypov, R. A.; Zverreva, M. G.; Shkuropatova, V. A.; Owens, T. G.; Shuvalov, V. A. FEBS Lett. 1999, 450, 163-167.

(69) Moënne-Loccoz, P.; Robert, B.; Latz, M. Biochem. 1989, 28, 3641-3645.

(70) Bylina, E. J.; Kirmaier, C.; McDowell, L.; Holten, D.; Youvan, D. C. Nature 1988, 336, $182-184$.

(71) Clyton, R. K.; Yamamoto, T.; Photochem. Photobiol. 1976, 24, 67-70.

(72) Diner, B. A.; Rappaport, F. Annu. Rev. Plant Biol. 2002, 53, 551-580.

(73) Konermann, L.; Holzwarth, A. R. Biochem. 1996, 35, 829-842. 
(74) Mimuro, M.; Tomo, T.; Nishimura, Y.; Yamazaki, I.; Satoh, K. Biochim. Biophys. Acta 1995, 1232, 81-88.

(75) Stewart, D. H.; Nixon, P. J.; Diner, B. A.; Brudvig, G. W. Biochem. 2000, 39, 1458314594.

(76) Rätsep, M.; Pieper, J.; Irrgang, K-D.; . Freiberg, A. J. Phys. Chem. B 2008, 112, 110-118.

(77) Steffen, M. A.; Lao, K.; Boxer, S. G. Science 1994, 264, 810-816.

(78) Reddy, N. R. S.; Kolaczkowski, S. V.; Small, G. J. Science 1993, 260, 68-71.

(79) Saito, K.; Ishida, T.; Sugiura, M.; Kawakami, K.; Umena, Y.;Kamiya, N.; Shen, J.-R.;

Ishikita, H. J. Am. Chem. Soc. 2011, DOI: 10.1021/ja203947k.

(80) Renger, T.; Schlodder, E. ChemPhysChem 2010, 11, 1141-1153.

(81) den Hartog, F. T. H.; Dekker, J. P.; van Grondelle, R.; Völker, S. J. Phys. Chem. B 1998, 102, 11007-11016.

(82) Groot, M.-L.; Dekker, J. P; van Grondelle, R.; den Hartog, F. T. H.; Völker, S. J. Phys. Chem. 1996, 100, 11488-11495. 
TOC graphics

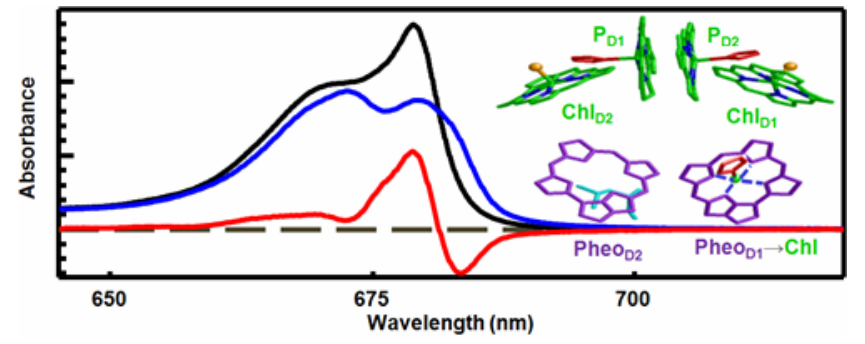

